\title{
Progress in chronic graft-versus-host disease
}

Paul J. Martin

Fred Hutchinson Cancer

Research Center, University of

Washington, Seattle, WA, USA

Conflict-of-interest disclosure:

The authors declare no competing

financial interest

Submitted: 6/16/2011

Accepted: 6/17/2011

Corresponding author:

Paul J. Martin

Fred Hutchinson Cancer Research Center

University of Washington

Seattle, WA, USA

pmartin@fncrc.org

www.rbhh.org or www.scielo.br/rbhh

DOI: 10.5581/1516-8484.20110071
The National Institute of Health $(\mathrm{NIH})$ consensus conference on criteria for clinical trials in chronic graft-versus-host disease (GvHD) brought fresh attention to a problem that is all too familiar to clinicians involved in hematopoietic stem cell transplantation. The series of 6 papers published in 2005 proposed new diagnostic criteria for the disease, summarized information regarding biomarkers and pathologic features associated with the disease, and offered recommendations for supportive care, measurement of response to treatment and the conduct of clinical trials. ${ }^{(1-6)}$

Subsequent publications have focused on efforts to validate the diagnostic criteria through retrospective studies and some additional work has been done to elucidate the significance of biomarkers, especially those indicating a possible role for B cells in the pathogenesis of the disease. In the United States, Dr. Stephanie Lee organized a consortium of investigators in multiple centers to collect prospective data from a large cohort of incident and prevalent cases. These data are now being used to address several important questions, including the optimal methods for measuring ocular and oral involvement, the association of disease severity with quality of life and risk of mortality, and the prognostic significance of acute GvHD manifestations including cutaneous erythema and gastrointestinal and hepatic involvement. Ultimately, the results of these studies will be used to refine and validate recommendations that emerged from the NIH consensus conference, which were mostly based on expert opinion. 
In this issue of the Revista Brasileira de Hematologica e Hemoterapia, Vigorito and colleagues describe the initial results of work by a group of Brazilian investigators to develop a platform for collaboration in clinical trials related to chronic GvHD. ${ }^{(7)}$ These investigators translated the US prospective data forms into Portuguese and then tested their use in five Brazilian centers. To date, the study has enrolled 34 patients with chronic GvHD. The Brazilian group and their colleagues in the US are to be congratulated for this first demonstration that international collaborations in the field of chronic GvHD are feasible in an academic setting.

Much work lies ahead. The authors emphasize the theme that the Brazilian consortium is intended to serve as a platform for future collaboration in clinical trials. Better insight into the pathogenesis of chronic GvHD is needed in order to select treatments that are most likely to be effective and safe. Further discussion is needed in order to standardize eligibility criteria, organ and overall response criteria, and assessment time points in studies of secondary treatment for chronic GvHD. The "shared language" emerging from this standardization will facilitate informative comparisons of results between different studies. Even more importantly, benchmarks of success should be established from both retrospective and prospective cohorts so that adequately powered, rigorous phase II studies can be conducted with one-sample statistical methods to identify the most promising agents for testing in future phase III trials.

The case-report forms used by the US and Brazilian consortiums will benefit from further refinement, since their current length and complexity is likely to discourage physicians from enrolling patients in clinical trials. The analysis of data from the forms will help to identify the most reliable and useful items that should be retained in shorter and less complex report forms to be used for future clinical trials. Members of the Brazilian consortium are in a good position to suggest how the forms can be improved since they were not involved in the design. As a more important contribution, however, the current members should celebrate the success illustrated in this report as a way of recruiting additional Brazilian colleagues to join in this new international effort to improve the treatment of patients with chronic GvHD.

\section{References}

1. Filipovich AH, Weisdorf D, Pavletic S, Socie G, Wingard JR, Lee SJ, et al. National Institutes of Health consensus development project on criteria for clinical trials in chronic graft-versus-host disease: I. Diagnosis and staging working group report. Biol Blood Marrow Transplant. 2005;11(12):945-56.

2. Shulman HM, Kleiner D, Lee SJ, Morton T, Pavletic SZ, Farmer E, et al. Histopathologic diagnosis of chronic graft-versus-host disease: National Institutes of Health Consensus Development Project on Criteria for Clinical Trials in Chronic Graft-versus-Host Disease: II. Pathology Working Group Report. Biol Blood Marrow Transplant. 2006;12(1):31-47.

3. Schultz KR, Miklos DB, Fowler D, Cooke K, Shizuru J, Zorn E, et al. Toward biomarkers for chronic graft-versus-host disease: National Institutes of Health consensus development project on criteria for clinical trials in chronic graft-versus-host disease: III. Biomarker Working Group Report. Biol Blood Marrow Transplant. 2006; 12(2):126-37.

4. Pavletic SZ, Martin P, Lee SJ, Mitchell S, Jacobsohn D, Cowen EW, Turner ML, Akpek G, Gilman A, McDonald G, Schubert M, Berger A, Bross P, Chien JW, Couriel D, Dunn JP, Fall-Dickson J, Farrell A, Flowers ME, Greinix H, Hirschfeld S, Gerber L, Kim S, Knobler R, Lachenbruch PA, Miller FW, Mittleman B, Papadopoulos E, Parsons SK, Przepiorka D, Robinson M, Ward M, Reeve B, Rider LG, Shulman H,Schultz KR, Weisdorf D, Vogelsang GB; Response Criteria Working Group. Measuring therapeutic response in chronic graft-versus-host disease: National Institutes of Health Consensus Development Project on Criteria for Clinical Trials in Chronic Graft-versus-Host Disease: IV. Response Criteria Working Group report. Biol Blood Marrow Transplant. 2006;12(3):252-66.

5. Couriel D, Carpenter PA, Cutler C, Bolaños-Meade J, Treister NS, Gea-Banacloche J, et al. Ancillary therapy and supportive care of chronic graft-versus-host disease: national institutes of health consensus development project on criteria for clinical trials in chronic Graft-versus-host disease: V. Ancillary Therapy and Supportive Care Working Group Report. Biol Blood Marrow Transplant. 2006;12(4):375-96.

6. Martin PJ, Weisdorf D, Przepiorka D, Hirschfeld S, Farrell A, Rizzo JD, Foley R, Socie G, Carter S, Couriel D, Schultz KR, Flowers ME, Filipovich AH, Saliba R, Vogelsang GB, Pavletic SZ, Lee SJ. National Institutes of Health Consensus Development Project on Criteria for Clinical Trials in Chronic Graft-versus-Host Disease: VI. Design of Clinical Trials Working Group report. Biol Blood Marrow Transplant. 2006;12(5):491-505.

7. Vigorito AC, Bouzas LF, Moreira MC, Funke VA, Colturato VA, Pedro A, et al. A multicenter feasibility study of chronic graftversus-host disease according to the National Institute of Health (NIH) criteria: efforts to establish a Brazil-Seattle consortium as a platform for future collaboration in clinical trials. Rev Bras Hematol Hemoter. 2011;33(4):283-9. 